\title{
The Magma Feeding System of the Klyuchevskaya Group of Volcanoes (Kamchatka)
}

\author{
Academician E. I. Gordeev ${ }^{a, b, *}$, \\ Corresponding Member of the RAS I. Yu. Koulakov ${ }^{a, c}$, and N. M. Shapiro ${ }^{b, d}$ \\ Received April 22, 2020; revised May 21, 2020; accepted May 22, 2020
}

\begin{abstract}
Using observations from a large-scale seismic station network, we built a seismic tomography model of velocity anomalies for longitudinal ( $\mathrm{P}$-wave) and transverse ( $\mathrm{S}$-wave) seismic waves beneath the Klyuchevskaya group of volcanoes. The observational network (about $150 \mathrm{~km}$ ) and the number of seismic stations (about 200) made it possible to determine the velocity structure to depths of $150 \mathrm{~km}$. A low-velocity anomaly is observed almost beneath all volcanoes in the Klyuchevskaya group of volcanoes at a depth of $50 \mathrm{~km}$. Beneath the Shiveluch volcano, in the region where the subduction plate discontinues, an anomaly can be detected to depths of $150 \mathrm{~km}$. Most likely, in this zone, there is a channel for the penetration of magmatic melts to the surface along the boundary of the submerging Pacific Plate ending. This is indirectly confirmed by the presence of a mantle plume to a depth of $1000 \mathrm{~km}$, as previously shown by the seismic tomography studies and an anomalous heat flow at the junction of the Kuril-Kamchatka and Aleutian island arcs.
\end{abstract}

Keywords: Seismic tomography, magmatic source, Klyuchevskaya group of volcanoes, subduction DOI: $10.1134 / \mathrm{S} 1028334 \mathrm{X} 20080085$

In subduction zones, volcanism is characterized by a complicated mechanism of magmatic feeding. A volcano feeding system involves a multilevel system of magma chambers in the crust and upper mantle. Previous studies provided insight into the detailed structure of the medium to depths of $30 \mathrm{~km}$ for the Klyuchevskaya group of volcanoes [1-4]. For the Klyuchevskoi volcano, several magma chambers were detected on different levels of the crust. A significant volume of magmatic melts was revealed at a depth of $30-35 \mathrm{~km}$ on the crust-mantle boundary. These melts are the main feeding source for the Klyuchevskoi and Bezymyannyi volcanoes. According to long-term observations, heightened seismic activity is observed in this zone. This is due to the impact of magmatic melts and fluids on the surrounding solid medium.

\footnotetext{
${ }^{a}$ Institute of Volcanology and Seismology, Far East Branch, Russian Academy of Sciences, Petropavlovsk-Kamchatsky, 683006 Russia

${ }^{b}$ Schmidt Institute of Physics of the Earth, Russian Academy of Sciences, Moscow, 123995 Russia

${ }^{c}$ Trofimuk Institute of Petroleum Geology and Geophysics, Siberian Branch, Russian Academy of Sciences, 630090 Novosibirsk, Russia

${ }^{d}$ Institute Earth Sciences, CNRS, University Grenoble-Alpes, Grenoble, France

*e-mail: gordeev@kscnet.ru
}

The feeding system of the Klyuchevskoi volcano is a vertical channel. However, for the Bezymyannyi volcano, the long-lived magmatic volume [3] was established at shallow depths, where, most likely, magmatic melts are differentiated with a subsequent eruption of lighter andesite magmas. Previous studies provided seismic tomographic models of the medium structure beneath the Klyuchevskaya group of volcanoes on the basis of earthquake records for local seismic networks. Studies at great depths, which are related to the areas of the crust and mantle between the submerging slab and the Earth's surface, were limited because of the lack of observations on dense networks with a large aperture. Up to the present, a large-scale experiment on the registration of seismic events on temporary networks of more than 100 seismic stations with a network coverage of up to $150 \mathrm{~km}$ has been carried out in the area of the Klyuchevskaya group of volcanoes [5] (Fig. 1).

In addition to data obtained from the experiment, we used the records from the temporal seismic stations on the Tolbachic volcano for the period of 2014-2015 and data of the permanent stations on the network of the Kamchatka Regional Seismological Center, Geophysical Survey, Russian Academy of Sciences. The total number of the seismic stations (temporal and permanent) was 208 , and the total number of registered earthquakes was 6609. This volume of data allowed us to build a seismic tomography model to 


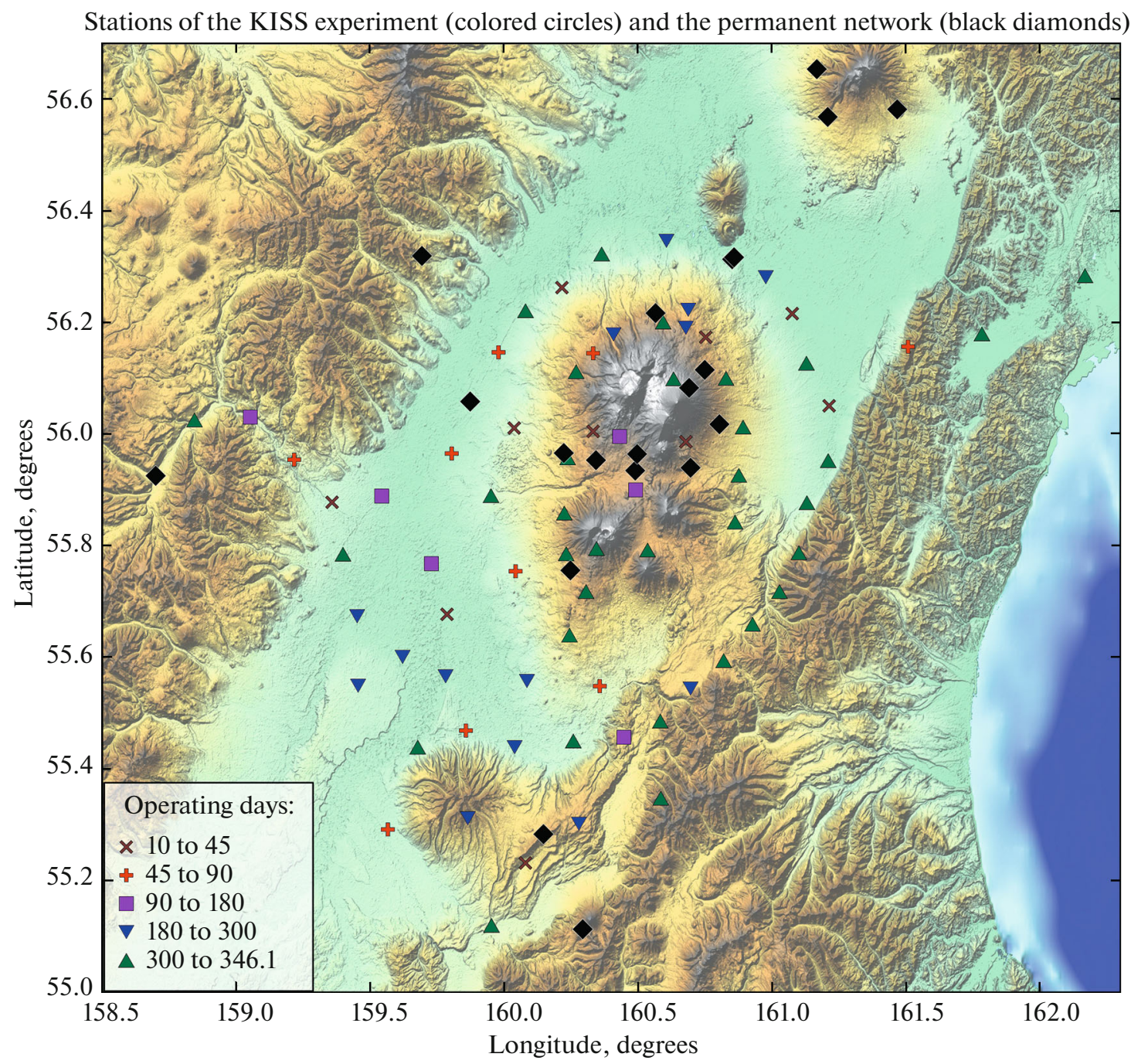

Fig. 1. Position of the seismic stations in the area of the Klyuchevskaya group of volcanoes in the period of observations from August 2015 to July 2016. A different color designates the stations with different intervals of continuous observations.

depths of $150 \mathrm{~km}$, up to the upper boundaries of the submerging subduction plate.

Figure 2 (to the left) shows the structure of longitudinal seismic waves (P-wave) at a depth of $50 \mathrm{~km}$ beneath the Klyuchevskaya group of volcanoes. A strong anomaly of lower velocities is well pronounced to the east of the Klyuchevskoi volcano. This anomaly is almost uniform for all volcanoes of the Klyuchevskaya group.

The Klyuchevskoi volcano feeding system from the upper boundary of the subduction plate is traced on the transversal sections along the $2 \mathrm{~A}-2 \mathrm{~B}$ profile (Fig. 3). The Tolbachik volcano feeding system is also connected with the subduction plate, which is illustrated in the section along the $3 \mathrm{~A}-3 \mathrm{~B}$ profile (Fig. 3).

When considering the anomalous structures along the 1A-1B profile (Kizimen-Shiveluch), the existence of a single anomalous body at depths from 30 to
$70 \mathrm{~km}$ is evident (Fig. 2). This anomaly is parallel to the subduction plate. In the area of the Shiveluch volcano, the anomaly submerges along the boundary of the slab end to depths of $150 \mathrm{~km}$. Unfortunately, the data obtained on the wide-aperture network of seismic stations in the area of the Klyuchevskaya group of volcanoes do not allow us to build a velocity model with a satisfactory resolution for deep zones. However, with the use of previous studies, the seismic tomographic velocity model was built based on earthquake records from the global seismic networks and all seismic stations of the Geophysical Survey, Russian Academy of Sciences, for the period from 1955 to 1997 for the junction zone of the Kuril-Kamchatka and Aleutian island arcs. This model illustrates a low-velocity subvertical anomaly to a depth of $1000 \mathrm{~km} \mathrm{[6].} \mathrm{This} \mathrm{man-}$ tle plume may well be a source of magmatic melts, which penetrate to the surface in the zone of the displacement caused by discontinuance of the submerg- 

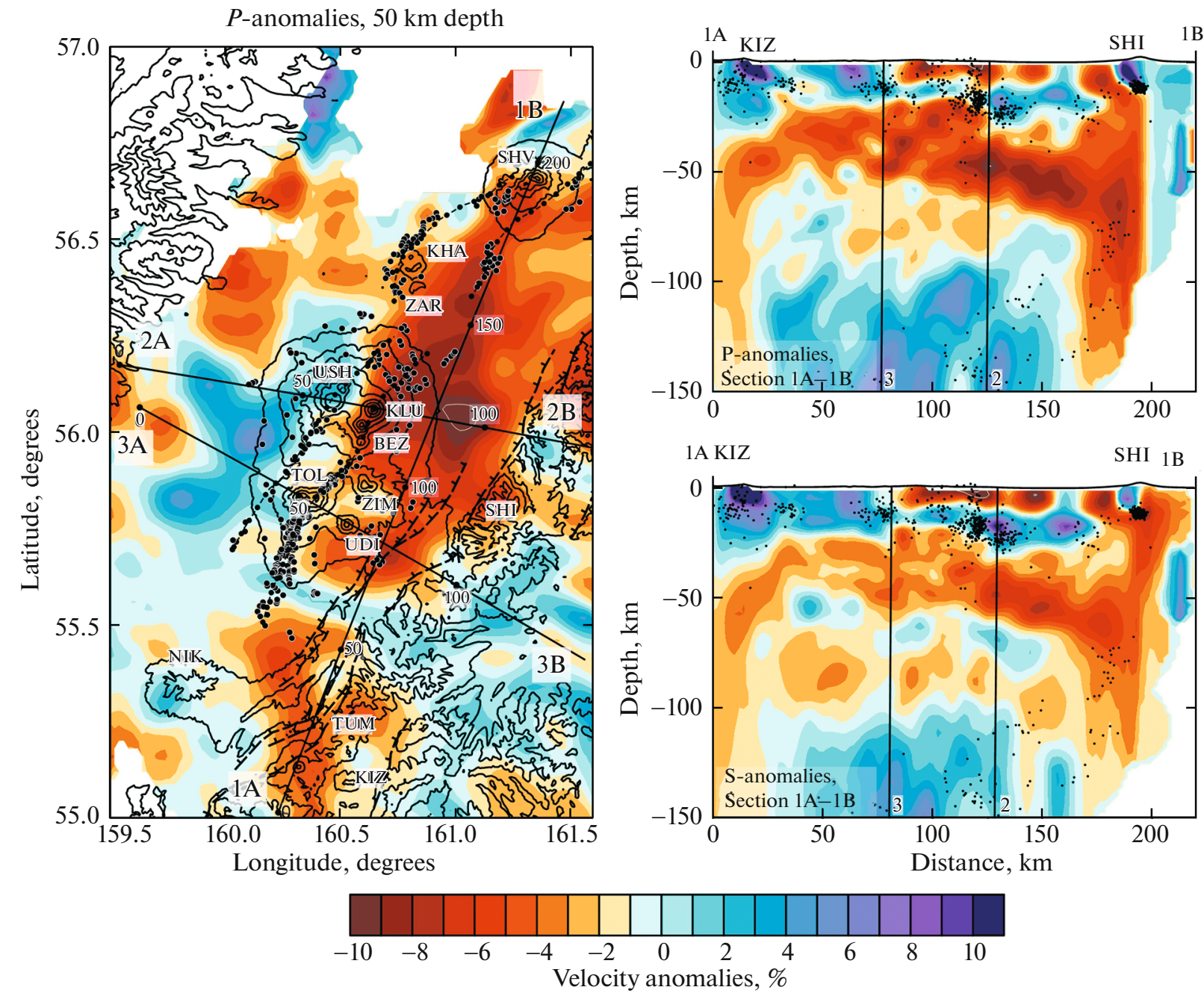

Fig. 2. The left image shows the structure of anomalies of $\mathrm{P}$-wave velocities beneath the Klyuchevskaya group of volcanoes at a depth of $50 \mathrm{~km}$. The right image shows velocity anomalies of longitudinal (P-wave) and transverse ( $\mathrm{S}$-wave) seismic waves on the deep section on the 1A-1B profile (Kizimen volcano-Shiveluch volcano). The hypocenters of earthquakes beneath volcanoes and in the zone of subduction are marked by dots.

ing Pacific Plate. This assumption is indirectly confirmed by the presence of heat flow on the sea bottom at the junction of the Kuril-Kamchatka and Aleutian island arcs [7].

Therefore, the seismic tomographic model of the velocity structure beneath the Klyuchevskaya group of volcanoes, which was built on a wide-aperture seismic network, is a system of magmatic volumes and feeding channels in the lower crust and the upper mantle. The presence of a mantle feeding source beneath the Shiveluch volcano is evident. This feeding system, most likely, was formed due to discontinuance of the slab on the northern end of the subducting oceanic plate. The hot asthenosphere with volatile constituents enters along the boundary of the subducting plate and provides the high activity of the Klyuchevskaya group of volcanoes. Figure 4 shows the tomographic model that was built based on regional data for the junction zone of the Kuril-Kamchatka and Aleutian island arcs at a depth of $150 \mathrm{~km}$ [8]. The position of the cool submerging plate and its discontinuance in the junction zone, where there is the heated asthenosphere, is traced.

For volcanoes of the Klychevskaya group, there is also a system in which the feeding is provided directly from the upper boundary of the submerging oceanic plate (Fig. 3). It is generally accepted that magmatic melts' generation is related to partial melting of the submerged plate in the subduction zones. A decrease in the melting point of the oceanic crust that composes the submerged plate at depths of about $100 \mathrm{~km}$ results in the formation of melts due to dehydration processes. Apparently, the main volcanoes of the Eastern Volcanic Belt of Kamchatka have this mechanism of the formation of magmatic melts. Assuming that the volcanoes of the Klyuchevskaya group are supplied by 

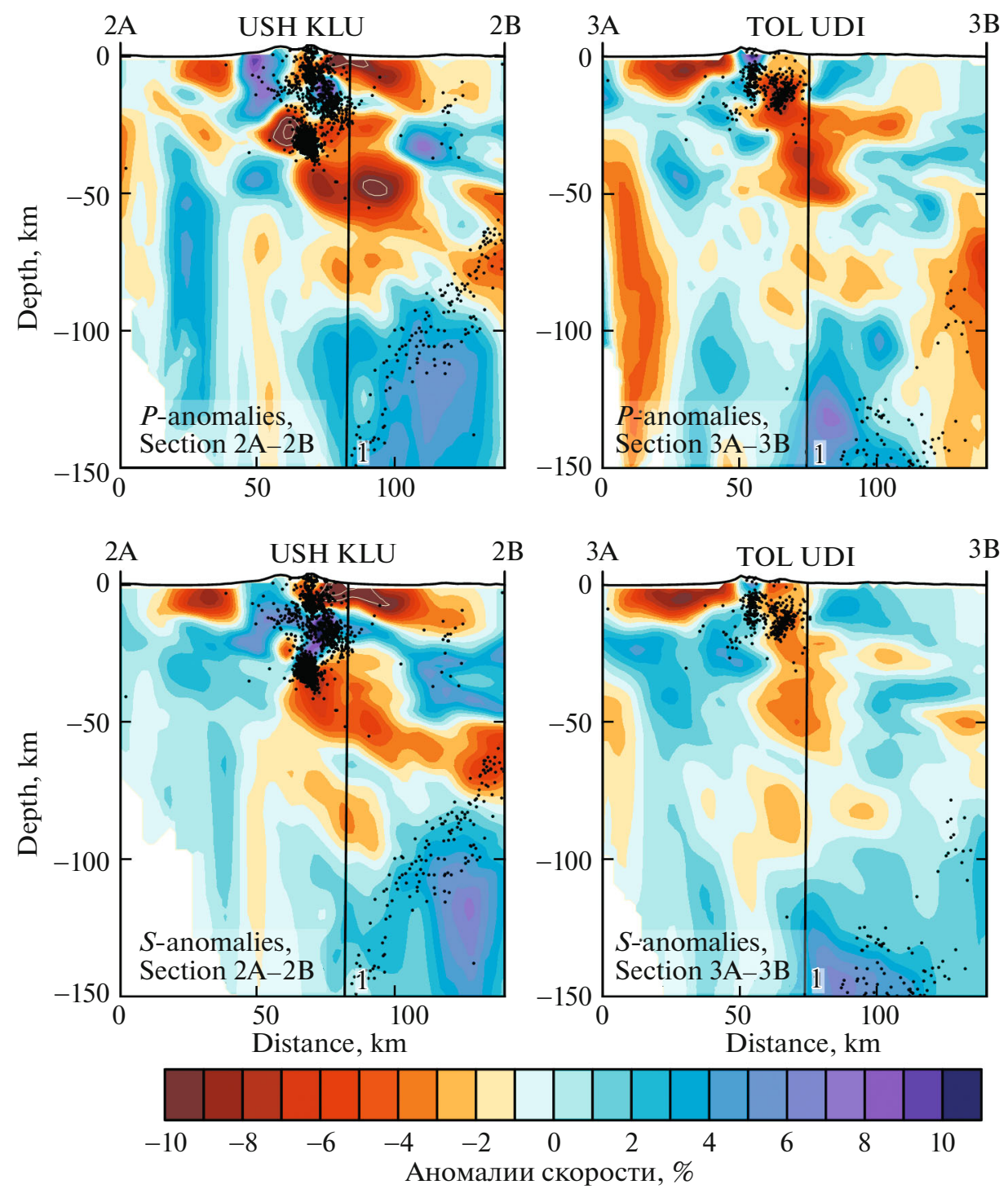

Fig. 3. The structure of anomalies of longitudinal (P-wave) and transverse ( $\mathrm{S}$-wave) seismic waves beneath the Klyuchevskaya group of volcanoes on the $2 \mathrm{~A}-2 \mathrm{~B}$ and $3 \mathrm{~A}-3 \mathrm{~B}$ sections from Fig. 2 . The hypocenters of earthquakes beneath volcanoes and in the subduction zone are marked by dots.

magmatic melts only from the submerging plate, their productivity has to be comparable to all volcanoes along the subduction zone. We compared erupted volcanic products for all Holocene volcanoes for the Klyuchevskaya group and the Eastern Volcanic Belt of Kamchatka.

The comparison was performed on the volumes of the volcanic edifices. Of course, this method is not quite correct, because explosive products of eruptions are not taken into consideration, but it is possible to obtain comparative characteristics. We estimated the volumes for 15 volcanic edifices of the Klyuchevskaya group and for 53 volcanic edifices of the Eastern Volcanic Belt. The productivity of the Klyuchevskaya group of volcanoes is 11 times higher than the productivity of all other Holocene volcanoes of the Eastern

Table 1. Comparison of the volcanic edifice volumes for the Holocene volcanoes of the Klyuchevskaya group and the Eastern Volcanic Belt

\begin{tabular}{l|c|c|c}
\hline \multicolumn{1}{c|}{ Groups of volcanoes } & Total volume, $\mathrm{km}^{3}$ & $\begin{array}{c}\text { Volume per unit area } \\
\text { of the plate, } \mathrm{km}^{3}\end{array}$ & Ratio \\
\hline Klyuchevskaya group of volcanoes & 1750 & 32 & 11 \\
Volcanoes of the Eastern Volcanic Belt & 1280 & 2.9 & 1 \\
\hline
\end{tabular}




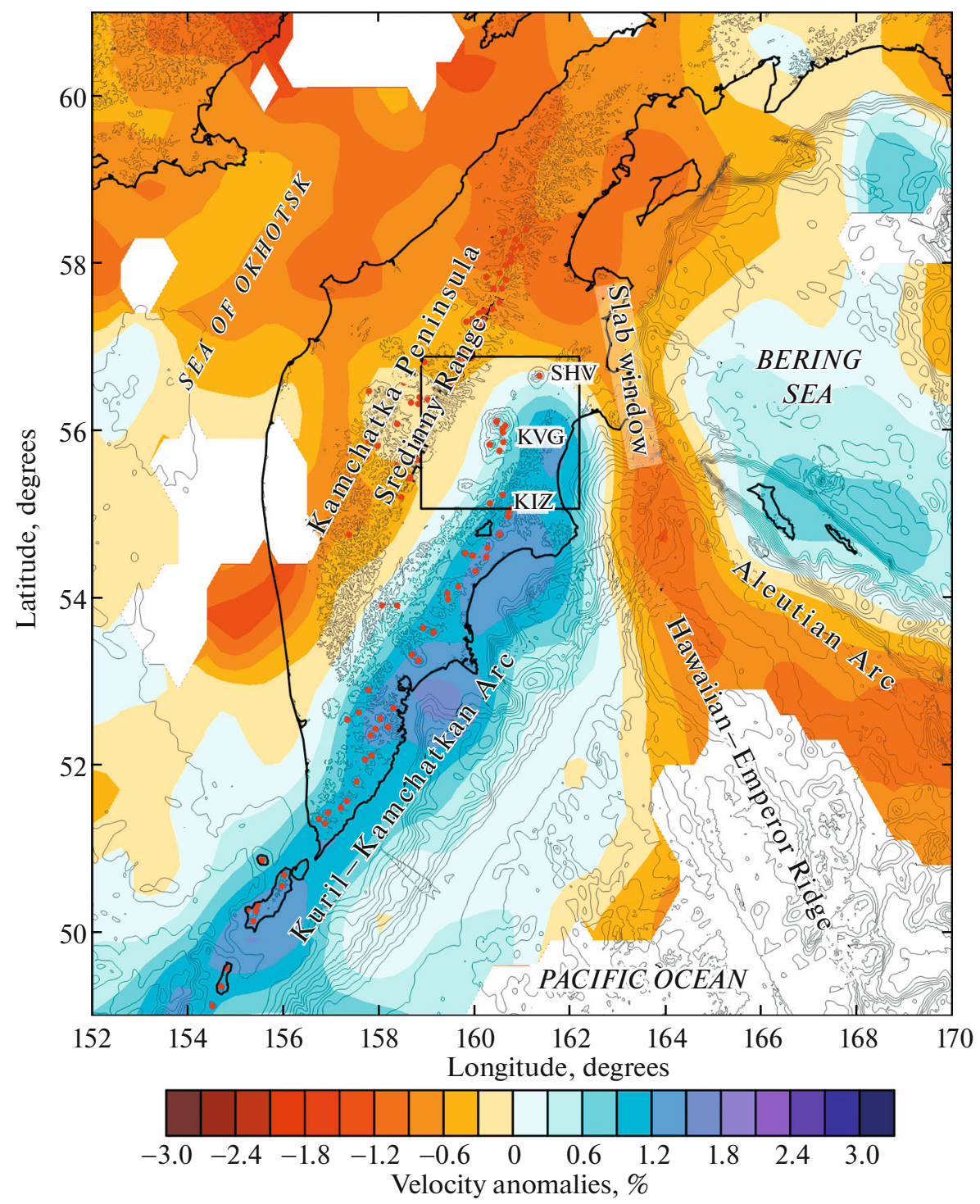

Fig. 4. The structure of velocity anomalies of longitudinal (P-wave) seismic waves in the junction zone of the Kuril-Kamchatka and Aleutian island arcs on a horizontal plane at a depth of $150 \mathrm{~km}$ in accordance with the model of regional tomography [8].

Belt. This can only be explained by the presence of additional sources of magma melts.

\section{FUNDING}

This work was supported by the Ministry of Education and Science of Russia, mega-grant 14W03.31.0033, and the Russian Foundation for Basic Research, project no. 18-5552003

\section{REFERENCES}

1. I. Koulakov, E. I. Gordeev, E. I. Dobretsov, et al., Geophys. Res. Lett. 38, L09305 (2011). https://doi.org/10.1029/2011GL046957

2. I. Koulakov, E. Kukarina, E. Gordeev, et al., Russ. Geol. Geophys. 57 (1), 82-94 (2016). https://doi.org/10.1016/j.rgg.2016.01.006
3. A. I. Ivanov, I. Yu. Koulakov, M. West, et al., J. Volcanol. Geotherm. Res. 323, 62-71 (2016). https://doi.org/10.1016/j.jvolgeores.2016.04.010

4. I. Koulakov, I. Abkadyrov, N. Al Arifi, et al., J. Geophys. Res. Solid Earth 122 (5), 3852-3874 (2017). https://doi.org/10.1002/2017JB014082

5. N. M. Shapiro, E. I. Gordeev, I. F. Abkadyrov, et al., Vestn. Dal'nevost. Otd. Ross. Akad. Nauk, No. 1, 7578 (2017).

6. A. Gorbatov, Y. Fukao, S. Widiyantoro, and E. Gordeev, Geophys. J. Int. 146, 282-288 (2001).

7. Ya. B. Smirnov and V. M. Sugrobov, Vulkanol. Seismol., No. 1, 16-31 (1980).

8. I. Y. Koulakov, N. L. Dobretsov, N. A. Bushenkova, and A. V. Yakovlev, Russ. Geol. Geophys. 52, 650-667 (2011). 